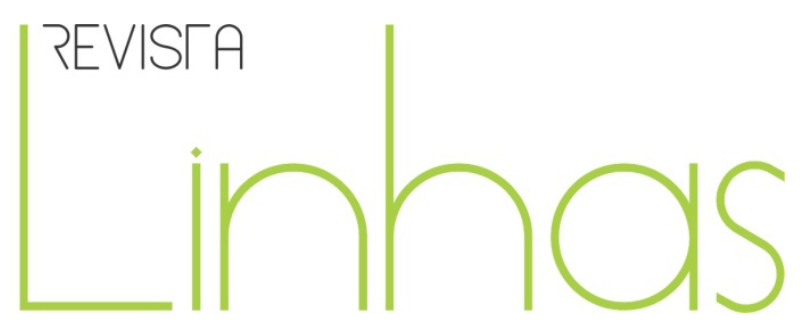

\title{
Os herdeiros: uma das principais "teses" da sociologia francesa da educação
}

\begin{abstract}
Resumo
Os herdeiros (1964) figura, passados mais de 50 anos, como essencial à consolidação dos estudos sociológicos da educação. Explicitar algumas das razões para retomar esta obra num outro momento histórico, num outro espaço geográfico, num outro contexto cultural é o objetivo deste artigo. Nossa inspiração vem do fato de se tratar de uma obra que permanece contemporânea graças às questões que discute e que, no caso brasileiro, pode contribuir para a reflexão crítica das políticas educacionais mais recentes. Ao pôr em xeque a retórica da democratização da educação, ao vincular educação e cultura, desigualdades sociais e desigualdades escolares por meio de algumas teses, Os herdeiros apresenta uma força crítica incontornável à compreensão das instituições de ensino, podendo ser lida como um apelo ao engajamento dos intelectuais nas grandes causas sociais e educacionais, além de se constituir uma contribuição importante para os definidores das políticas para a educação nacional.
\end{abstract}

Palavras-chave: Democratização da educação; Educação e cultura; Desigualdades sociais; Desigualdades escolares; Políticas educacionais.

\author{
Ione Ribeiro Valle \\ Doutora em Ciências da \\ Educação pela Universidade \\ René Descartes - Paris V \\ Sorbonne - França \\ ione.valle@ufsc.br
}

\footnotetext{
Para citar este artigo:

VALLE, Ione Ribeiro. Os herdeiros: uma das principais "teses" da sociologia francesa da educação. Revista Linhas. Florianópolis, v. 15, n. 29, p. 232-250, jul./dez. 2014.
}

DOI: $10.5965 / 1984723815292014232$

http://dx.doi.org/10.5965/1984723815292014232 


\title{
The Inheritors: one of the main "theses" of the French sociology of Education
}

\begin{abstract}
The Inheritors (1964) remains, after more that 50 years, essential to the construction of the sociological studies in education. The aim of this article is to explain the reasons to retake the work in another historical moment, in another geographic space, in another cultural context. We draw our inspiration from the fact that it is a work that is still contemporary due to the questions it discusses and that, in the Brazilian context, to a critical reflection of the most recent educational policies. By showing the inconsistency of the rhetoric of democratization of education, by linking together education and cultural, social inequalities and school inequalities by means of certain theses, The Inheritors presents an inescapable to the understanding of the school institutions, and can be read as an appeal to the commitment of the intellectuals in big social causes, besides the fact that it constitutes an important contribution to those who define policies for the national education.
\end{abstract}

Keywords: Democratization of education; Education and culture; Social inequalities; School inequalities; Educational policies. 
Se o universo escolar evoca por mais de uma forma o universo do jogo,

campo de aplicação de regras que somente valem quando se aceita jogar, espaço e tempo limitados, delimitados, arrancados do mundo real no qual pesam os determinismos, é porque, mais do que outro jogo, ele propõe ou impõe aos jogadores a tentação de prender-se no jogo levando a crer que coloca todo seu ser em jogo.

Pierre Bourdieu e Jean-Claude Passeron (1964)

Hoje, como há meio século, Os herdeiros (1964) aparece como uma referência essencial à compreensão das desigualdades escolares; hoje, tanto quanto há 50 anos, aposta-se no ideal meritocrático porque se acredita que são os dons e a performance escolar que possibilitam a cada um melhorar sua situação social; hoje, mais do que há meio século, apesar da paisagem educacional ter se modificado consideravelmente, esta obra figura como leitura imprescindível quando se trata de desvelar lógicas de reprodução social, historicamente dissimuladas pelo poder simbólico exercido pela escola.

Estas seriam algumas das razões para ler Os herdeiros num outro momento histórico, num outro espaço geográfico, num outro contexto cultural. Estas também foram as principais motivações para a tradução de mais esta obra de Pierre Bourdieu, elaborada em parceria com Jean-Claude Passeron. Não se trata, evidentemente, de uma motivação ditirâmbica ou de uma decisão obcecada pela abordagem multifacetada e polêmica que caracteriza a obra. O que nos inspira é, sobretudo, o desejo de conhecer uma espécie de libido sciendi - o fio de ligação entre as obras dedicadas especificamente à educação: Os herdeiros sendo a primeira obra deste quádruplo, seguida de $A$ reprodução (publicada na França em 1970 e lançada no Brasil em 1975, num momento crítico da ditadura militar), de Homo academicus (publicada na França em 1984 e lançada no Brasil em 2011 pela Editora da UFSC) e de A nobreza de estado (publicada na França em 1989 e que ainda não foi traduzida para o português). 
As duas primeiras obras (Os herdeiros e A reprodução) são fruto de uma parceria de mais de uma década entre Pierre Bourdieu e Jean-Claude Passeron. Uma parceria que teve altos e baixos e que foi sintetizada por Passeron na seguinte frase: "Com Bourdieu, contra Bourdieu". Esta frase, segundo ele, define com precisão a influência que Bourdieu teve sobre sua trajetória de sociólogo e de cientista social. Ela expressa também a contribuição de Bourdieu sobre todos os que trabalharam com ele ou entraram em contato com sua "imaginação sociológica”.

É nesta "imaginação sociológica”, inscrita numa tradição científica que foi ao mesmo tempo reativada e subvertida, que buscamos os elementos que vão orientar nossa reflexão neste momento. Ou seja, só tem sentido ler Os herdeiros meio século depois se considerarmos que se trata de uma obra que marca a mudança na trajetória da sociologia da educação, ciência que nos anos 1960 ainda se encontrava em seu estado embrionário. Sabemos que o pensamento contemporâneo está enraizado nos conhecimentos que antecederam o nosso tempo, ou, mais precisamente, no pensamento clássico. Nele encontramos as lentes que ajudam a compreender grande parte das questões que continuam desafiando pesquisadores e administradores da educação.

Como se pode perceber uma das razões para ler Os herdeiros deve-se ao fato de se tratar de uma obra clássica. Para caracterizá-la como tal, apoiamo-nos na definição apresentada por Ítalo Calvino (escritor italiano, 1923-1985, nascido em Cuba) na obra Porque ler os clássicos? (1981) $)^{1}$ Para Calvino (1993, p.7-8), “dizem-se clássicos aqueles livros que constituem uma riqueza para quem os tenha lido e amado; mas constituem uma riqueza não menor para quem se reserva a sorte de lê-los pela primeira vez nas melhores condições de apreciá-los"

Uma segunda razão para ler Os herdeiros é sua contemporaneidade. Vivemos num mundo marcado por crises políticas, pela queda de alguns muros e edificação de outros, por rupturas epistemológicas, pela reafirmação de doutrinas fundamentalistas que colocaram em xeque os grandes ideais que animaram até muito recentemente a chamada era moderna. Todavia, apesar dos inúmeros avatares que têm atingido as

\footnotetext{
${ }^{1}$ Disponível em <http://www.ufrgs.br/proin/versao_1/porque/index.html>, acesso em 09.03.2014.
} 
últimas décadas, a Escola e, mais recentemente, a Universidade permanecem alvo das mais veementes demandas sociais. Embora as críticas sejam crescentes e cada vez mais contundentes, estas instituições continuam sendo consideradas como uma possibilidade, talvez a única, de conquista da justiça social num mundo dominado pelas múltiplas cores das injustiças.

No Brasil, à medida que vivenciamos importantes mudanças econômicas, sociais, políticas e culturais, por longas décadas reivindicadas, percebemos que o acesso à Escola e a ampliação das oportunidades de formação superior, fruto de políticas educacionais voltadas à democratização da educação, em nenhum momento foram postos em dúvida. Ao contrário, o que vemos é a passagem da escolarização como obrigação (referimo-nos à clássica obrigatoriedade escolar que remonta ao século $\mathrm{XIX}^{2}$ ) para a escolarização como direito.

Vale lembrar que numa sociedade democrática os cidadãos são juridicamente iguais e, portanto, cada um é potencialmente candidato às posições sociais e profissionais, indiferentemente de suas características pessoais e das suas condições de nascimento. E é nessa dinâmica de distribuição que a educação escolar permanece sendo considerada como uma instituição promotora da justiça, pois cabe a ela preparar os indivíduos, segundo seus dons e méritos, para a ocupação dessas posições.

No entanto, sabemos que é por meio das políticas de escolarização que as desigualdades sociais têm se convertido em desigualdades escolares. E, apesar da literatura sociológica mais recente revelar o alto grau de legitimidade da instituição escolar no que tange fundamentalmente à promoção de desigualdades justas, constatase sistematicamente que as posições sociais de maior prestígio são desigualmente distribuídas, altamente hierarquizadas e valorizadas.

No caso brasileiro, cada vez mais o prolongamento dos estudos e a obtenção de diplomas que permitem o acesso a essas posições é posto em perspectiva, como mostram as lutas pela escolarização, da educação infantil ao ensino superior. O diploma aparece, portanto, como emblema da justiça social e como dispositivo a ser

\footnotetext{
${ }^{2}$ Sobre a obrigatoriedade escolar no Brasil ver Vidal, Sá e Silva (2013).
} 
disponibilizado a todos porque ele é a expressão mais legítima do mérito (individual). Com isso, como lembra François Dubet (2009, p. 21), se "atribui à escola a carga esmagadora de ser a única instituição capaz de distribuir legitimamente os indivíduos em posições desiguais".

Como se pode ver, a contemporaneidade de Os herdeiros está no fato de revelar as contradições entre o que se promete e o que se realiza quando se trata de pôr em prática dois princípios (igualdade e meritocracia) fundantes das políticas educacionais. Estamos nos referindo, portanto, a finalidades-chave, retomadas e ressignificadas pelas diferentes políticas educacionais que atravessaram o século XX. Estes mesmos princípios estão na agenda das políticas para a educação do novo milênio e justificam projetos, programas e diversificadas ações governamentais. Vale ressaltar que a igualdade de acesso permanece associada a uma grande confiança na escola emancipadora e libertadora.

\section{De um continente a outro}

Ao pôr a nu a vinculação direta e mecânica entre desigualdades sociais e desigualdades escolares, a obra Os herdeiros atira pimenta nos olhos dos legisladores e administradores da educação francesa da década de 1960. Desde então, muitas mudanças foram introduzidas no sistema de ensino daquele país; reformas se sucederam como reação ao fracasso comprovado das políticas de democratização da educação denunciado em Os herdeiros.

O que vemos hoje? Uma França que, passados 50 anos, foi elevando a barra de acesso aos níveis escolares (a meta hoje é formar 50\% da população no nível superior), sem, contudo, democratizar verdadeiramente a educação escolar. Os estudos continuam mostrando que os "herdeiros" são maioria nas posições escolares de prestígio, que os "herdeiros" ainda ocupam o que há de mais primoroso no sistema francês de educação, seja nos colégios, nos liceus, nas universidades ou nas grandes escolas; que os "herdeiros" continuam vivendo "seu destino como vocação". 
E para nós brasileiros qual poderia ser a importância de Os herdeiros? Ela está no fato de termos um sistema de ensino, da educação infantil à educação superior, marcado por desigualdades que se cruzam e se multiplicam, impedindo dessa maneira de se vislumbrar, mesmo ao longo prazo, um processo de escolarização o menos injusto possível. Nosso sistema de ensino se caracteriza por um fosso profundo entre os princípios que regem a educação nacional - a igualdade de oportunidades sendo o princípio norteador - e as desigualdades da oferta. Ainda temos 8,5\% de analfabetos (com diferenças regionais que variam de $4,4 \%$ no Sul do Brasil a $17,4 \%$ no Nordeste) $)^{3}$.

Embora possamos comemorar a quase massificação do ensino fundamental, estamos longe de oferecer a educação básica às novas gerações: 50\% das crianças de 0 a 5 anos estão fora da educação infantil; 50\% dos jovens de 15 a 19 anos não frequentam o ensino médio ${ }^{4}$. A realidade no ensino superior é ainda mais gritante apesar do aumento de quase 150\% do número de instituições de ensino superior entre 1998 e 2008: menos de 10\% destas instituições são universidades; menos de 7\% são públicas ${ }^{5}$.

\section{Tradições, diálogos, racionalidade pedagógica}

O que encontramos em Os herdeiros? Gostaria de destacar ao menos quatro dimensões, que mostram o "espírito do tempo", expresso no modo de fazer sociologia dos dois pensadores. Primeiramente a força crítica, reunindo a crítica (fruto da posição científica exercida no campo profissional) e a crítica da crítica (fruto de suas posições políticas). Uma crítica bem elaborada, empiricamente bem sustentada e produzida no quadro de um trabalho coletivo e interdisciplinar; único capaz de escapar do "efeito de gueto" ao qual se expõem os pesquisadores enclausurados em seus mundos acadêmicos

\footnotetext{
3 Cf.: Mapa Brasil. Disponível: http://www.achetudoeregiao.com.br/ATR2/mapa_brasil.htm. Acesso em 10.10.2013.

4 Cf.: Ministério da Educação. Censo escolar. Disponível: http://download.inep.gov.br/educacao_basica/censo_escolar/resumos_tecnicos/resumo_tecnico_censo_ed ucacao_basica_2012.pdf. Acesso em 10.10.2013.

${ }^{5}$ Cf.: BRASIL. IBGE. Evolução da Educação Superior/1991-2007. Disponível: <http://www.inep.gov.br/superior/censosuperior/sinopse/default.asp>. Acesso em 10.10.2013; BRASIL. IBGE. Sinopses Estatísticas da Educação Superior, $2008 . \quad$ Disponível: <http://www.inep.gov.br/superior/censosuperior/sinopse/default.asp>. Acesso em 10.10.2013.
} 
(BOURDIEU, 2001, p. 17). Certamente, é a força da crítica que mais nos interessa como pesquisadores e intelectuais engajados ou como "intelectual coletivo", nos termos apresentados por Bourdieu ${ }^{6}$. A dimensão crítica aparece claramente na conclusão de Os herdeiros, quando os autores assinalam que "não é suficiente constatar que a cultura escolar é uma cultura de classe e tudo fazer para que ela permaneça assim, agindo como se ela fosse somente isso" (BOURDIEU e PASSERON, 2014, p. 97).

A obra inaugura, como se pode ver, um novo "jeito" de fazer sociologia, porque institui um modus operandi, retomado, de forma mais elaborada e detalhada em $A$ profissão de sociólogo (publicada em 1968), numa parceria com Jean-Claude Passeron e Jean-Claude Chamboredon; obra que propõe uma visão de conjunto da realidade, porque se distingue da visão intuitiva e de controle predominante, e supõe um controle total do objeto tendo como base o conjunto das informações levantadas e não "certos rituais de purificação ideológica" (PESTAÑA, 2012, p. 363).

Pierre Bourdieu incorpora, como verdadeira obsessão, esse modo de fazer sociologia e vai lapidando-o nas obras que vão se sucedendo; Meditações pascalianas (1997) representando sua construção teórica mais elaborada graças às suas precisões epistemológicas. Jean-Claude Passeron, por sua vez, também leva adiante a necessidade de redefinir a prática sociológica, embora percorra outros caminhos e desenvolva de outra maneira seu "raciocínio sociológico" (obra publicada em 1991).

É, portanto, na base de construção de Os herdeiros que situamos tanto o apelo ao engajamento do intelectual nas grandes causas sociais e, neste caso, educacionais, quanto o ideal de objetividade científica que deve deixar de lado as preferências normativas ou ideológicas. Em Os herdeiros firma-se uma sociologia fiel à sua vocação de “desnaturalizar" os fenômenos humanos visando desfatalizá-los; uma sociologia que

\footnotetext{
6 "Inspirado no conceito de Foucault de 'intelectual específico', esse modelo de engajamento pauta-se na especialização e na divisão do trabalho de expert propondo uma forma de ação coletiva fundada no acúmulo de competências num determinado domínio do conhecimento. Ao contrário do individualismo do mundo das letras onde reina o paradigma da singularidade, esse modelo remete ao modo de funcionamento do campo científico pautado no trabalho em equipe e na acumulação de conhecimentos, inaugurando um modo coletivo de intervenção política com base no trabalho científico" (SAPIRO, 2009, p. 30).
} 
apreende as ferramentas cognitivas com as quais se pensa o mundo como ferramentas de natureza profundamente social.

Uma segunda dimensão a ser destacada nesta obra é o lugar atribuído à empiria: quase $40 \%$ dela é dedicada à apresentação dos dados levantados por meio de enquetes visando a construção da tese central. Esses dados aparecem em tabelas e gráficos que mostram como as sociedades se estruturam, se perpetuam, se reproduzem, se transformam. Esta dimensão analítica é decorrente, evidentemente, da preocupação com o fazer sociológico. Em Os herdeiros, Bourdieu e Passeron inovam ao desenvolver uma perspectiva crítica, radical, a partir de análises quantitativas, tendo recorrido ao que havia de mais avançado em termos estatísticos. Segundo eles, ainda que se conte com uma disponibilidade estatística fraca, é possível interpretar relações estatísticas mais gerais. Eles procuram, portanto, superar a ilusão da interpretação fácil e imediata da realidade, entendendo que esta deve ser controlada por meio da análise estatística, única capaz de permitir o estabelecimento de regularidades e a construção de totalidades estruturais.

Vale lembrar que, à época, esse tipo de análise era identificado com as práticas funcionalistas, era definido como de orientação positivista e, portanto, denunciado pelo ser caráter alienador e dissimulador dos modos de dominação de classe. É o esforço de superação da dicotomia objetivismo/subjetivismo, de revisão de posicionamentos decorrentes de uma "sociologia espontânea" que, muitas vezes, se confunde com uma sociologia erudita, que começam a ser experimentados nesta obra, passando a dar o tom ao conjunto de estudos desenvolvidos pelos autores, pelos que com eles trabalharam e, mesmo, por aqueles que deles divergem.

A terceira dimensão que queremos enfatizar diz respeito ao caráter propositivo de Os herdeiros. A obra não se distingue pelo "pessimismo", amplamente denunciado poucos anos mais tarde, ao contrário, ela contempla uma aposta na pedagogia desde que efetivada com base nos fundamentos sociológicos. Ao mostrar o caráter irreal de todas as reformas pautadas exclusivamente na psicologia, os autores evocam a chamada “pedagogia racional”, fazendo referência à necessária "racionalização da pedagogia”. Trata-se de uma pedagogia "fundada numa sociologia das desigualdades culturais, [que] sem dúvida contribuiria para reduzir as desigualdades diante da escola e da cultura", mas 
somente poderia se concretizar se fossem "oferecidas todas as condições de uma democratização real do recrutamento dos mestres e dos alunos" (BOURDIEU e PASSERON, 2014, p. 101). Esta concepção atravessa o texto e, embora tenha permanecido inacabada, "abre uma perspectiva de transformação possível, em ruptura tanto com um funcionalismo fechado quanto com as ilusões filosófico-político-pedagógicas de uma esquerda erudita" (GEAY, 2012, p. 99).

A última dimensão refere-se à gênese das principais categorias de análise, ou de tipos ideais, construídos por Pierre Bourdieu e objeto de constantes reformulações nas suas obras subsequentes (A distinção, 1979; O senso prático, 1980; culminado com suas Meditações pascalianas, 1997), a saber: capital, campo, habitus, distinção, violência simbólica. Mas, neste momento, gostaria de destacar a originalidade de algumas das suas teses sociológicas, as quais se tornaram centrais no campo dos estudos sociológicos da educação. Evidentemente, não se trata de teses independentes, uma vez que só têm sentido no quadro do pensamento relacional.

Referimo-nos primeiramente à herança cultural; categoria de análise que dá sustentação ao tipo ideal elaborado para Os herdeiros. Esta tese foi acolhida na época por sua originalidade ao mostrar que os fatores sociais de desigualdade perante a escola são bem mais complexos que os simples fatores de desigualdade social. É nesta tese que são lançadas as bases para a elaboração da noção de capital cultural, o que vai ocorrer por meio da análise de variáveis relacionadas à boa vontade cultural, à devoção à cultura, à incitação cultural, à ortodoxia cultural. Estas noções estão relacionadas às virtudes reconhecidas e valorizadas, ao diletantismo dos estudantes, à noção de vanguarda política e estética, às ideias de familiaridade e desenvoltura na relação com a vida universitária. Nesta tese é explorada a conivência do "herdeiro" com o mundo escolar em razão da sua origem burguesa e culta, o que lhe permite dominar - e mobilizar - os códigos culturais e escolares adquiridos na família e na socialização escolar de base. Essa constatação é confirmada pelos ritos de iniciação, redefinidos em obras posteriores como ritos de instituição, tais como: O que falar quer dizer; a economia das trocas linguísticas (1982) e A dominação masculina (1998), por exemplo. 
Uma segunda tese que merece destaque é a vinculação direta entre desigualdades sociais e desigualdades escolares. Observe-se que estamos falando de desigualdades sociais e não apenas de desigualdades econômicas. Esta tese, construída a partir da análise das condições sociais de origem dos estudantes universitários, mobilizados para a edificação do tipo ideal “herdeiro”, coloca em evidência

\begin{abstract}
a ação direta dos hábitos culturais e das disposições herdadas do meio de origem [sublinhando que as mesmas são redobradas] pelo efeito multiplicador das orientações iniciais (também produzidas pelos determinismos primários), as quais desencadeiam a ação de determinismos induzidos ainda mais eficazes quando se exprimem na lógica propriamente escolar, sob a forma de sanções que consagram as desigualdades sociais sob a aparência de ignorá-las. (BOURDIEU e PASSERON, 2014, p. 30)
\end{abstract}

Como se pode ver, esta tese apresenta uma crítica contundente do princípio meritocrático, um dos principais pilares dos sistemas modernos de ensino, explicitando suas ilusões e hipocrisias. Dom, mérito, vocação (que permanecem hipotéticos), assim como os demais dispositivos facilitadores do acesso à escola (como as bolsas de estudo, por exemplo), nada mais são que mecanismos de legitimação dos privilégios dos bemnascidos.

A terceira tese que pode ser extraída do conjunto das análises de Os herdeiros diz respeito às múltiplas faces das desigualdades (de classe, de sexo, de oportunidades, de dom, de privilégio cultural, de chances de acesso ao ensino superior). Os autores observam uma ligação estreita entre morfologia social e categorias cognitivas por meio dos mecanismos de seleção, que nada mais são que dispositivos legitimadores dessa máquina de reprodução: "Lê-se nas chances de acesso ao ensino superior o resultado de uma seleção que, ao longo de todo o percurso escolar, exerce-se com um rigor muito desigual segundo a origem social dos sujeitos; na verdade, para as classes mais desfavorecidas, trata-se puramente e simplesmente de eliminação" (BOURDIEU e PASSERON, 2014, p. 16). Anuncia-se aqui o efeito cascata das desigualdades, o qual seria retomado mais tarde por meio da noção de "indiferença às diferenças", desenvolvido 
principalmente em $A$ reprodução. Esta tese explica - e justifica - a escolha escolar, a docilidade escolar, particularmente no caso das mulheres.

Uma quarta tese a ser destacada na obra Os herdeiros refere-se à noção de cultura universal vista como arbitrário cultural. Os percursos individuais são determinados pela proximidade que existe entre a cultura de classe de um aluno e a cultura de classe legitimada e transmitida pela escola. Os autores observam que há correspondência e continuidade entre o arbitrário escolar e o habitus de classe, pois "Crer que são dadas a todos oportunidades iguais de acesso ao ensino mais elevado e à cultura [...] é ficar no meio do caminho na análise dos obstáculos e ignorar que as aptidões medidas pelo critério escolar" apresentam grande afinidade com os hábitos culturais de uma classe e as exigências do sistema de ensino (BOURDIEU e PASSERON, 2014, p. 39). Desta maneira, a ficção de uma competição entre iguais se torna credível uma vez que os "muito desiguais" ficam fora do jogo escolar. Esse mecanismo além de criar condições de trabalho harmoniosas leva os "herdeiros" a atribuírem a causa das injustiças escolares unicamente às injustiças sociais, a pouca ambição do povo e, sobretudo, às diferenças de dons (DUBET, 2002, p. 134-135). O que esta perspectiva coloca em evidência é a forte tensão entre igualdade e mérito, relativamente neutralizada pelas políticas de democratização da educação.

A quinta tese levantada para esta reflexão é a mais polêmica da obra de Bourdieu. Estamos nos referindo à tese da reprodução, formulada em Os herdeiros por meio da menção aos determinismos sociais, ao ethos de classe e da competição, às vantagens e desvantagens cumulativas, à ascensão pela escola, à vontade de diferenciação, ao sucesso escolar como sinal de eleição, às diferenças de privilégios, ao destino social, ao futuro objetivo, ao princípio e função da seleção. Esta tese também se evidencia no fenômeno de autosseleção, nas profecias autorrealizadoras e nos argumentos mobilizados para trabalhar a variável precocidade. Os autores assinalam que

a cultura da elite é tão próxima da cultura da escola que a criança originária de um meio pequeno-burguês (e $a$ fortiori camponês ou operário) só pode adquirir laboriosamente o que é dado ao filho da classe culta, o estilo, o gosto, o espírito, enfim, esses saberes e esse saber-viver que são naturais a uma classe, porque são a 
cultura dessa classe. Para uns, a aprendizagem da cultura da elite é uma conquista, pela qual se paga caro; para outros, uma herança que compreende ao mesmo tempo a facilidade e as tentações da facilidade. (BOURDIEU e PASSERON, 2014, p. 41-42)

A última tese a ser evocada neste momento está relacionada à singularidade do mundo escolar. Esta tese é fruto do deslocamento do olhar do sociólogo para o interior da escola, ou do mundo universitário em particular, por meio da análise das expectativas professorais, dos critérios de julgamento professoral, do carisma professoral, da devoção escolar, da relegação num curso, da repetência, da resignação, da medida do sucesso escolar, do zelo escolar. Esses fatores presentes na dinâmica interna da escola e dos processos e mecanismos pedagógicos são analisados - e somente podem ser analisados - na relação com a dinâmica que move o sistema de ensino, ou seja, na relação de forças externas ao mundo escolar que determinam a transformação do capital herdado em capital escolar, reafirmando, assim, as fronteiras sociais. Observe-se, por exemplo, o caso da dissertação: ela é vista como "pretexto para julgar homens, ou, ao menos, o homem universitário" (BOURDIEU e PASSERON, 2014, p. 65). Esta reflexão foi retomada em seguida, em 1966, num artigo de Bourdieu publicado na revista Actes de la recherche en sciences sociales, intitulado A escola conservadora, cujo objetivo foi analisar as desigualdades diante da escola e da cultura. Mas seu aprofundamento se daria em A reprodução (1970) é apresentada a tese da "violência simbólica", que se dá na convergência entre ação pedagógica, autoridade pedagógica, trabalho pedagógico e sistema de ensino. Por violência simbólica se entende essa violência doce, invisível, desconhecida como tal, tanto escolhida quanto submetida, como a confiança, a obrigação, a fidelidade pessoal, a hospitalidade, a doação, a dívida, o reconhecimento, a piedade. Enfim, todas as virtudes que honram a moral do honrado e que se impõem como o modo de dominação mais econômico por estar mais conforme com a economia do sistema (BOURDIEU, 1980, p. 219). 


\section{Dessacralizando a escola e a universidade}

Enfim, a leitura de Os herdeiros permite perceber a instituição escolar a partir de outras lentes. Esta obra interessa, portanto, a nós pesquisadores, aos formadores dos novos quadros do magistério e aos definidores e administradores das políticas para a educação nacional. Vemo-nos e sentimo-nos engajados na superação do atraso em termos do direito à educação, dos recém-nascidos aos adultos que, no caso brasileiro, foram sendo deixados à margem de um sistema de ensino, que, como se viu, cresceu de maneira considerável.

Ao dirigirmos um olhar crítico sobre as políticas educacionais, buscamos na tradição sociológica parâmetros de compreensão. Esta ciência sempre atribuiu um lugar central à instituição escolar no que concerne ao seu papel na produção e reprodução das sociedades. Tudo começa com o lugar atribuído à educação na obra de Émile Durkheim na virada do século XX. Ao menos uma de suas obras merece destaque nesta nossa reflexão, não apenas porque focou a educação escolar associando fins e meios, mas, sobretudo, porque teve grande importância na arquitetura do sistema educacional brasileiro. Refiro-me principalmente à obra Educação e sociologia (DURKHEIM, 1978), traduzida por Lourenço Filho e publicada no Brasil em 1928

Com o passar do tempo e com o desenvolvimento e consolidação dos sistemas de ensino, o alvo passou a ser os fins da educação escolar, particularmente no que concerne às funções de integração e regulação social vislumbradas por Durkheim e postas em prática pelas políticas educacionais que se propuseram a promover a coesão e a ordem. O que se observou desde então foi o descompasso entre a massificação da educação e a distribuição das posições sociais e profissionais. Ou, dizendo de outra maneira, a igualdade de oportunidades escolares não tornou a sociedade mais meritocrática, pois as posições de prestígio foram mantidas nas mãos dos "herdeiros". Além disso, o desenvolvimento das condições da igualdade de oportunidades acentuou a competição entre as famílias, entre as áreas e cursos, entre os diversos segmentos dos sistemas educacionais. Diante desse quadro, permanece pertinente a interrogação sobre 
a responsabilidade da instituição escolar na produção e reprodução das desigualdades sociais.

Motivadas por diversas construções teóricas, mas também pelo caráter militante de algumas das teorias sociológicas, as abordagens mais recentes procuraram articular diferentes níveis de análise, do mais macro ao mais micro. Elas vêm completar as análises de Bourdieu e Passeron que privilegiaram as desigualdades decorrentes da distância entre as culturas familiares e as culturas escolares.

Os sociólogos, particularmente na França, vêm desenvolvendo uma quantidade considerável de análises empíricas, tornando essa área da sociologia um campo particularmente produtivo. Esses estudos têm fundamentado as abordagens críticas da educação brasileira, principalmente após a abertura do regime político. Além disso, eles têm sido apropriados, nem sempre com o rigor necessário, pelos setores produtores das políticas educacionais para o nosso país.

Voltando às desigualdades escolares, e ao mesmo tempo finalizando, é preciso reconhecer que a primeira desigualdade está ligada ao fato de acessar ou não à Escola e à Universidade. Esse é, indiscutivelmente, o primeiro passo para a concretização da chamada "justiça como equidade", apresentada por John Rawls (2002) e que se constitui hoje numa espécie de fio orientador, ou talvez condutor, de grande parte das ações dos nossos sistemas de ensino.

Por outro lado, não se pode esquecer que a expansão das redes de ensino é uma faca de dois gumes. Ela é, ao mesmo tempo, uma reforma equalizadora e uma contrarreforma, pois assegura aos mais favorecidos a manutenção de suas vantagens. Esta constatação nos leva a considerar que a igualdade de oportunidades é uma norma de justiça extremamente cruel porque coloca sobre os alunos - e unicamente sobre os seus ombros - a responsabilidade pelos seus sucessos e pelos seus fracassos, uma vez que a equidade da competição estaria garantida. François Dubet (2008) lembra que há algo "darwiniano" na igualdade meritocrática das oportunidades.

Para finalizar, gostaria de assinalar que a leitura de Os herdeiros permite sublinhar algumas características da instituição escolar que podem servir de base para a elaboração 
de uma crítica aprofundada da Escola e da Universidade. Para tanto, retomamos alguns elementos apresentados por Adelino Braz (2011), que podem servir de ponto de partida para essas análises. Segundo ele, a instituição escolar deve ser apreendida como um instrumento de conservação porque tende a produzir e a reproduzir dispositivos que asseguram a perpetuação do poder das classes mais favorecidas, ou a reafirmar a cultura legítima; deve ser observada como um instrumento de dominação uma vez que favorece, pela complexidade de seus mecanismos pedagógicos, o desconhecimento desse sistema de reprodução social dissimulado pela ideia de eficácia, e, enfim, deve ser tratada como um instrumento de legitimação da ordem social que se explica pelo fato de que os agentes atribuem às estruturas objetivas da ordem escolar estruturas de apreciação incorporadas produzidas por essas mesmas estruturas.

Todavia, é preciso deixar claro que nossa intenção se distancia do pessimismo e da desmobilização. Ao contrário, o que desejamos é, sobretudo, apreender os contornos da complexa teoria de Pierre Bourdieu e de seus colaboradores, suas contribuições, seus limites, alguns de seus pontos de tensão. O que esperamos é reafirmar a importância do trabalho investigativo porque ele permite desvelar a lógica que está por detrás das práticas educacionais. Todo esforço está em se apropriar da sociologia como uma "arma" para compreender o mundo que nos cerca, para dar um sentido àquilo a que estamos presos e, dessa maneira, assumir uma distância reflexiva que permita orientar a ação. Todo desafio está em se apropriar da reflexão sociológica desencadeada por esses dois autores para tentar compreender o quadro de injustiças que caracteriza a educação contemporânea, a partir da ruptura epistemológica introduzida pela teoria das práticas sociais desde a década de 1960. O que se deve evitar evidentemente é o fascínio produzido pela profusão de conceitos e de esquemas teóricos e pela força do léxico elaborado por Bourdieu, o qual é de fácil utilização e adaptação. Isto tem provocado apropriações indevidas e imitações estéreis pelos que transformam, à moda antiga, "seu mestre de pesquisa em mestre de pensamento" (PASSERON, 2005, p. 90).

Enfim, ler uma obra que acendeu o pavio da contestação estudantil de Maio de 1968 (PASSERON, 2005, p. 72) e que nutriu uma geração de estudantes revolucionários que não deveriam ser revolucionários (VIDAL-NAQUET, 2005, p. 95) somente se justifica 
se reconhecermos, como Ítalo Calvino (1993, p. 9), que "os clássicos são livros que exercem uma influência particular quando se impõem como inesquecíveis e também quando se ocultam nas dobras da memória, mimetizando-se como inconsciente coletivo ou individual".

\section{Referências}

BOURDIEU, Pierre. A distinção. Porto Alegre: Zouk, 2007. (Publicado originalmente em francês, 1979).

BOURDIEU, Pierre. A dominação masculina. Rio de Janeiro: Bertrand Brasil, 2002 (Publicado originalmente em francês, 1998).

BOURDIEU, Pierre. A economia das trocas lingüísticas: o que falar quer dizer. São Paulo: Edusp, 1998 (Publicado originalmente em francês, 1982).

BOURDIEU, Pierre. A escola conservadora: as desigualdades frente à escola e à cultura. In NOGUEIRA, Maria Alice; CATANI, Afranio. Escritos de educação. 2. ed. Petrópolis: Vozes, 1999. p. 39-64. (Publicado originalmente em francês, 1966).

BOURDIEU, Pierre. Homo academicus. Florianópolis: UFSC, 2011. (Publicado originalmente em francês, 1984).

BOURDIEU, Pierre. La noblesse d'État: grandes écoles et esprit de corps. Paris: Minuit, 1989.

BOURDIEU, Pierre. Le sens pratique. Paris: Minuit, 1980.

BOURDIEU, Pierre. Méditations pascaliennes. Paris: Seuil, 1997.

BOURDIEU, Pierre. Science de la science et réflexivité. Paris: Raisons d'Agir, 2001.

BOURDIEU, Pierre; CHAMBOREDON, Jean-Claude; PASSERON, Jean-Claude. A profissão de sociólogo: preliminares epistemológicas. Petrópolis: Vozes, 1999. (Publicado originalmente em francês, 1968). 
BOURDIEU, Pierre; PASSERON, Jean-Claude. A reprodução: elementos para uma teoria do sistema de ensino. Rio de Janeiro: Francisco Alves, 2. ed. 1982. (Publicado originalmente em francês, 1970).

BOURDIEU, Pierre; PASSERON, Jean-Claude. Os herdeiros: os estudantes e a cultura. Florianópolis, 2014 (Publicado originalmente em francês, 1964).

BRASIL. Ministério da Educação. Mapa do analfabetismo. Brasília, 2008. Disponível: http://www.achetudoeregiao.com.br/ATR2/mapa_brasil.htm. Acesso em 10.10.2013.

BRAZ, Adelino. Bourdieu et la démocratisation de l'éducation. Paris: PUF, 2011.

CALVINO, Ítalo. Porque ler os clássicos? Local, 1993. Disponível:

http://www.ufrgs.br/proin/versao_1/porque/index.html. Acesso em 09.03.2014.

DUBET, François. Le déclin de l'institution. Paris: Seuil, 2002.

DUBET, François. Le travail des sociétés. Paris: Seuil, 2009.

DUBET, François. O que é uma escola justa? a escola das oportunidades. São Paulo: Cortez, 2008 (Publicado originalmente em francês em 2004).

DURKHEIM, Émile. Educação e sociologia. 11.ed. Rio de Janeiro: Melhoramentos, , 1978.

GEAY, Bertrand. Éducation et culture. La nouvelle infrastructure? In LEBARON, Fréderic e MAUGER, Gérard (Dir.). Lectures de Bourdieu. Paris: Ellipses, 2012, p. 95-110.

IBGE. evolução da educação superior/1991-2007. Rio de Janeiro, [data], Disponível: <http://www.inep.gov.br/superior/censosuperior/sinopse/default.asp >. Acesso em 10.10.2013.

IBGE. Sinopses estatísticas da educação superior, 2008. Rio de Janeiro, data. Disponível: <http://www.inep.gov.br/superior/censosuperior/sinopse/default.asp >. Acesso em 10.10.2013.

PASSERON, Jean-Claude. Morte de um amigo, fim de um pensador. In ENCREVÉ, Pierre ; LAGRAVE, Rose-Marie. Trabalhar com Bourdieu. Rio de Janeiro: Bertrand Brasil, 2005, p. 17-91.

PASSERON, Jean-Claude. O raciocínio sociológico: o espaço não-popperiano do raciocínio natural. Petrópolis: Editora Vozes, 2008 (Publicado originalmente em francês, 1991).

PESTAÑA, José Luis Moreno. Pierre Bourdieu ; PASSERON, Jean-Claude In LEBARON, Fréderic ; MAUGER, Gérard (Dir.). Lectures de Bourdieu. Paris: Ellipses, 2012, p. 353-372.

RAWLS, John. Uma teoria da justiça. 2.ed. São Paulo: Martins Fontes, , 2002. (Publicado originalmente em inglês em 1971). 
VIDAL, Diana Gonçalves; SÁ, Elizabeth Figueiredo; GASPAR da SILVA, Vera Lucia (Orgs.). Obrigatoriedade escolar no Brasil. Cuiabá: EdUFMT, 2013.

VIDAL-NAQUET, Pierre. Lembranças intermitentes. In ENCREVÉ, Pierre e LAGRAVE, RoseMarie. Trabalhar com Bourdieu. Rio de Janeiro: Bertrand Brasil, 2005, p. 93-98.

Recebido em: 14/09/2013 Aprovado em: 27/02/2014

Universidade do Estado de Santa Catarina - UDESC Programa de Pós-Graduação em Educação - PPGE Revista Linhas Volume 15 - Número 29 - Ano 2014 revistalinhas@gmail.com 